ISSN: 1641-4713; e-ISSN: 2081-1160

DOI: https://doi.org/10.36551/2081-1160.2020.25.123-149

\title{
A luta pela terra e as políticas públicas territoriais no espaço agrário amazônico: uma reflexão a partir do assentamento Mártires de Abril em Belém
}

\author{
The Struggle for Land and Territorial Public Policies in the Amazonian \\ Agrarian Area: A Reflection from the Settlement of Martyrs of April in Belém
}

\author{
Danillo Vaz Costa \\ Universidade do Estado do Pará, Brasil \\ ID ORCID: https://orcid.org/0000-0002-5847-2663 \\ E-mail: danillo_vaz11@hotmail.com \\ Fabiano de Oliveira Bringel \\ Universidade do Estado do Pará, Brasil \\ ID ORCID: https://orcid.org/0000-0002-8380-9096 \\ E-mail: fabianobringel@gmail.com
}

Recepción: 15.02.2019

Aprobación: 21.04.2020

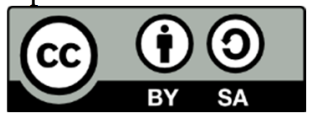

Resumo: O presente artigo tem por objetivo discutir a gestão pública e o campesinato na Amazônia e sua importância para a sociedade brasileira assim como a luta pela terra e os impactos dos movimentos sociais na construção e ocupação dos territórios. Utilizando como objeto de pesquisa o Assentamento Mártires de Abril localizado em Mosqueiro no município de Belém que representa uma perspectiva relevante para a reforma agrária apontando as principais dificuldades do assentamento frente ao descaso do poder público para com a agricultura familiar camponesa. Assim, para sistematizar tal artigo, os procedimentos de pesquisa têm abordagem qualitativa, tendo como instrumento os dados obtidos por intermédio de entrevistas e visitas de campo que auxiliaram no melhor entendimento da realidade abordada. Essa pesquisa tem como intuito dialogar sobre a necessidade de maiores investimentos do poder público no setor de agricultura familiar que cada vez mais mostra-se o principal produtor alimentício para a população brasileira, além de discutir ao longo deste texto a importância dos assentamentos para a implementação da reforma agrária.

Palavras-chave: Amazônia, gestão pública, políticas públicas territoriais, agricultura familiar camponesa, Belém do Pará. 


\begin{abstract}
This article discusses public management and peasantry in the Amazon and its importance to Brazilian society as well as the struggle for land and the impact of social movements in the construction and occupation of territories. It uses as an example the settlement Martyrs of April located in Mosqueiro in the municipality of Belém that represents a relevant perspective for agrarian reform pointing out the main difficulties of the settlement against the lack of power to peasant family farming. Thus, to systematize this article, the research procedures have a qualitative approach, using as a tool the data obtained through interviews and field visits that provide a better understanding of the reality addressed. The aim of this research is to discuss the need for greater public power investments in the family farming sector, which is increasingly shown as the main food producer for the Brazilian population. In addition this essay discusses throughout this text the Importance of settlements for the implementation of agrarian reform.
\end{abstract}

Keywords: Amazon, public management, territorial public policies, peasant family farming, Belém do Pará.

\title{
INTRODUÇÃO
}

A cidade de Belém possui um território físico de aproximadamente $1059,458 \mathrm{~km}^{2}$, onde mais de $65 \%$ de sua área é de domínio das 42 (quarenta e duas) ilhas, dentre as quais se situa o distrito administrativo de Mosqueiro $\left(211,7923 \mathrm{~km}^{2}\right)$, localizado a $70 \mathrm{~km}$ de distância do centro de capital paraense. O constante problema da precariedade nos investimentos públicos nas áreas das ilhas de Belém em contraste com a importância dessa área rural e sua dimensão fomentou a elaboração deste artigo com o seguinte tema: "A Luta Pela Terra e as Políticas Públicas Territoriais no Espaço Agrário Amazônico: Uma Reflexão a Partir do Assentamento Mártires de Abril em Belém" em que se propõe uma análise da interferência do poder público nas áreas insulares do município de Belém, utilizando como pano de fundo a luta pela terra e suas influências na região, tendo como objeto de estudo o núcleo de assentamento "Mártires de Abril" do Movimento dos Trabalhadores Rurais Sem Terra localizado na ilha de Mosqueiro em Belém.

As políticas públicas, em um sentido mais amplo, de acordo com Leslie Pal (Sabourin, 2017: 2) são "uma série de ações ou inações que autoridades públicas escolhem adotar para regular ou responder a um problema ou um conjunto de problemas interligados." Para Rua (2014) as políticas públicas partem de decisões e ações que resultam em destinação de verbas para bens públicos. Partindo deste ponto, o artigo buscou analisar o modo de vida camponês na região e qual a influência das políticas públicas nesse "dialogismo". Outro aspecto abordado é a importância do AMA (Assentamento Mártires Abril) para o movimento social do campo e para o MST, contribuindo também para uma embrionária reforma agrária brasileira. 
Utilizamos como recorte geográfico a Ilha de Mosqueiro, localizada a mais de $70 \mathrm{~km}$ do centro de Belém e que possui uma área de $212 \mathrm{~km}^{2}$, com o intuito de espacializar e melhor estudar a relação campo/cidade por meio desse objeto. Desse modo, escolhemos o Assentamento Mártires de Abril, em que de acordo com dados levantados pelo INCRA mais de 400 famílias residem no local e que representa grande conquista para luta pela reforma agrária e para o campo.

A fim de chegar aos resultados dessa pesquisa, será utilizado o método qualitativo, que na concepção de Chizzotti (2003)

Impropriamente e, às vezes, ironicamente, é designada pesquisa leve (soft), realizada no convívio com pessoas e fatos, oposta às ciências que se auto denominam duras (hard), realizadas na impessoalidade dos dados, nas clausuras laboratoriais ou em laboriosas exegeses estatísticas (2003: 223).

Com o objetivo de melhor analisar o objeto em estudo, utilizamos dados quantitativos coletados pelo Instituto Brasileiro de Geografia e Estatística (IBGE), assim como uma série de trabalhos de campo, que de acordo com as autoras Lakatos e Marconi (2003: 186) "consiste na observação de fatos e fenômenos tal como ocorrem espontaneamente, na coleta de dados a eles referentes e no registro de variáveis que se presume relevantes, para analisá-los."

A necessidade de analisar registros como fotos e documentos é extremamente importante para entender o a realidade do AMA, assim como da observação direta e intensiva a partir de entrevistas pré-elaboradas no modelo qualitativo, formuladas com características de diálogo com o intuito de tornar o contato pesquisador-objeto mais próximo. Para o embasamento teórico, utilizamos autores como Rodrigo Peixoto para elucidar a questão de políticas públicas territoriais, Geipel e Neuburger para abordar política, Fernandes e Raffestin para discutir o território, além de outros autores que foram fundamentais para substanciar este artigo.

O artigo será dividido em três partes, o primeiro tópico será responsável pela discussão teórica acerca do território e sua relação com os modos de vida camponeses, o tópico seguinte buscará debater o conceito de camponês que é abordado neste trabalho e o terceiro e último tópico cuidará da análise da relação dos investimentos de políticas públicas territoriais no Assentamento Mártires de Abril na Ilha de Mosqueiro em Belém do Pará. Em suma, o artigo fecha com uma conclusão e provocação para a construção de um debate que busque contribuir para o estudo dos diferentes agricultores familiares camponeses na Amazônia, assim como também, América Latina. 


\section{O TERRITÓRIO E OS MOVIMENTOS SOCIOTERRITORIAIS E SUA IMPORTÂNCIA} NA REFORMA AGRÁRIA

Grande parte dos movimentos sociais tem o espaço como objeto de luta, sendo o território o objetivo final dos conflitos. Há uma necessidade nas ciências humanas e sociais de discussão sobre a importância do estudo de movimentos sociais e seus impactos no espaço. Para Raffestin (1993), toda produção espacial é também uma territorialização, pois

Toda prática espacial, mesmo embrionária, induzida por um sistema de ações ou de comportamentos se traduz por uma "produção territorial" ... É interessante destacar a esse respeito que nenhuma sociedade, por mais elementar que seja, escapa à necessidade de organizar o campo operatório de sua ação. (1993: 150).

Ainda em Raffestin (1993), o poder está presente no território, pois

Os homens "vivem", ao mesmo tempo, o processo territorial e o produto territorial por intermédio de um sistema de relações existenciais e/ou produtivistas. Quer se trate de relações existenciais ou produtivistas, todas são relações de poder, visto que há interação entre os atores que procuram modificar tanto as relações com a natureza como as relações sociais. (1993: 158-159)

A sociedade é o principal agente modificador do espaço, e os movimentos sociais têm papel fundamental na luta por espaços e, consequentemente, pelo território. A própria construção de um território, seja por parte dos poderes públicos (Estado) ou de outros agentes, é uma fragmentação do espaço (Fernandes, 2008). Entender a perspectiva de Bernardo Mançano Fernandes para o território enquanto mecanismo de intervenção de políticas públicas no espaço é fundamental para a compreensão das dinâmicas territoriais que abrangem os povos tradicionais camponeses, pois para o autor essas "transformações do espaço acontecem pelas relações sociais no processo de produção do espaço" (Fernandes, 2008: 277). O Estado enquanto gestor desse espaço, predominantemente, ignora as diferentes territorialidades presentes em um mesmo território, reafirmando desigualdades e comprometendo a realidade de cada grupo.

Para Fernandes (2008: 278) “a definição de 'território’ por órgãos governamentais e agências multilaterais não consideram as conflitualidades dos diferentes tipos de territórios contidos 'território' de um determinado projeto de desenvolvimento territorial", ou seja, a própria problemática levantada pelo autor reforça essa questão de que "os diferentes territórios que se formam com conflitualidade expressa pelas relações de subalternidade e resistência do campesinato ao agronegócio" percebendo que "a luta pela terra é a luta por um determinado tipo de território: o território campesino" (Fernandes, 2008: 274), nesse ponto 
percebemos a importância que o território tem para os movimentos sociais do campo, o Movimento dos Trabalhadores Rurais Sem Terra exemplifica a luta e a necessidade da busca pelo território camponês, este que é negado por agentes hegemônicos que inviabilizam a reprodução do modo de vida camponês.

Destacando a importância das relações sociais e dos movimentos sociais sendo por meio destes que o território se efetiva e são por eles destituídos, se a força dessas relações sociais se extingue ou se novos grupos sociais conquistam esses espaços o território se reconfigura, assumindo novos interesses e novo organização. A força dos movimentos sociais reestrutura o território e combatem aos privilégios de grupos hegemônicos. Com isso Martin e Fernandes (2004: 2) afirmam que "as lutas de classes intervêm na produção do espaço, cujas classes, frações e grupos de classes são os sujeitos", é a partir da luta nos movimentos sociais que os grupos oprimidos conseguem ter espaço e direitos dentro da sociedade.

A busca pelo território é um dos fatores que move os movimentos sociais, a busca pelo e por um espaço que possua a identidade do movimento é o maior dos objetivos dos movimentos socioterritoriais, a necessidade de territorializar, pois

Do mesmo modo que alguns movimentos transformam espaços em territórios, também se territorializam e são desterritorializados e se reterritorializam e carregam consigo suas territorialidades, suas identidades territoriais constituindo uma pluriterritorialidade. A transformação do espaço em território acontece por meio da conflitualidade, definida pelo estado permanente de conflitos no enfretamento entre as forças políticas que procuram criar, conquistar e controlar seus territórios. (Fernandes, 2005: 30)

Os movimentos socioterritoriais enfrentam constantemente barreiras provenientes do Estado que dificultam sua permanência no espaço, dentre os diversos movimentos socioterritoriais presentes no campo, o Movimentos dos Trabalhadores Rurais Sem Terra (MST) é um dos mais expressivos no processo de luta pela terra e que ao longo dos anos assentou 350 mil $^{1}$ famílias no Brasil.

A luta pela reforma agrária se configura como uma das principais políticas públicas territoriais de busca pelo território camponês no Brasil, nos últimos anos essa reforma se consolidou baseada no número de assentamentos e ocupações provenientes da luta dos movimentos do campo e que de acordo com o relatório do INCRA foram assentados somente no ano de 2016 cerca de 27.412.1951 ha com capacidade para 1.012 famílias. Em contrapartida, do ano de $2017 \mathrm{em}$ diante - durante o governo Temer - não houve nenhum registro de famílias assentadas, o que demonstra um expressivo descaso do governo para com a reforma agrária e com a agricultura familiar, ou seja, temos uma contradição entre a importância econômica-social e os investimentos destinados a agricultura familiar.

\footnotetext{
${ }^{1}$ Recuperado de: http://www.mst.org.br/nossa-producao/
} 


\section{O CAMPESINATO LATINO AMERICANO: A LUTA, A TERRA, O TRABALHO} E A FAMÍLIA

Há a necessidade de discussão acerca do conceito de campesinato para dar prosseguimento ao diálogo reflexivo que nos propomos neste artigo. Assim, utilizamos - e utilizaremos - com frequência o termo "agricultura familiar" como condição de organização e não como fonte teórico argumentativa deste artigo. É importante elucidar que diversos trabalhos dentro da ciência agrária foram e são importantes para a estruturação do conceito de agricultura familiar (Abramovay, 1992), no entanto, a partir dos estudos desenvolvidos pela pesquisa podemos perceber que o campesinato brasileiro não é definido exclusivamente pelo "mercado" e sim pela luta da terra. Essa luta é expressada pela ocupação da terra e pelos diversos embates políticos entre o campesinato e o Estado - assim como contra grandes proprietários de terra, empresas estrangeiras e o sistema capitalista como um todo. É essa especificidade que incorpora ao termo campesinato a luta e a resistência, o que configura a história do campo

Para entender o campesinato brasileiro é necessário entender os impactos e influências que o sistema capitalista tem sobre o espaço agrário. Alguns teóricos da agricultura familiar consideram inimaginável a permanência do modo de vida campesina coexistir com o sistema capitalista e para isso há a necessidade dessa classe se desintegrar e transformar-se em agricultura familiar. Todavia é importante entender, como nos demonstra Martin e Fernandes (2004: 13), que a "organização do trabalho familiar no campo existe desde os primórdios da história da humanidade" e que coexistiram com os diferentes tipos de sociedade (escravista, feudal, capitalista e socialista) e se sua desintegração não aconteceu no capitalismo como previsto por esses teóricos, o campesinato resiste através da luta pela terra, como também por meio de relações não capitalistas de produção e por estratégias que o campesinato tem de executar para poder se reproduzir (Bartra, 2011).

É inegável que o campesinato utilize do trabalho familiar como principal força de produção, no entanto, definir como agricultura familiar é desprezar a trajetória de luta camponesa e desconstruir o modo de vida camponês. Outro ponto importante é a superação do campesinato por sua constante abordagem enquanto modo de produção frágil, pois vai de encontro a atual situação da luta camponesa (como acontece por meio da Via campesina) e a unificação dos diferentes grupos camponeses em prol de sua permanência enquanto modo de produção (reprodução) e vida em uma análise de unificação e luta campesina pela sua permanência 
frente ao avanço do capitalismo. Shanin (2005) ao determinar as principais características do campesinato elucida que

o cerne de suas características determinantes parece repousar na natureza e na dinâmica do estabelecimento rural familiar, enquanto unidade básica de produção e meio de vida social. Consequentemente, a própria existência do camponês, como uma entidade social específica, depende da presença de estabelecimentos rural familiares como a unidade básica da economia e da sociedade. O camponês deve ser compreendido, portanto, através da investigação das características do estabelecimento rural familiar camponês, tanto internas quanto externas, isto é, suas especificidades, reações e interações com o contexto social mais amplo. (2005: 5)

Definir os diferentes "camponeses" em um único e simples conceito de agricultor familiar é desprezar a heterogeneidade do trabalhador camponês, é criar dissonância conceitual na análise acerca do campesinato por meio da estruturação do termo agricultura familiar, no entanto, devemos atentar em compreender a heterogeneidade do campesinato sem desconsiderar características que assemelhem os diferentes camponeses, como afirma Teodor Shanin (2005: 3), as "normas e cognições típicas e muito semelhantes têm sido percebidas em campesinatos suficientemente afastados para obstar qualquer afirmação de simples dispersão", ou seja, o conhecimento utilizado (e transmitido) entre as comunidades camponesas (ou de acordo com Lefebvre: la comunidad rural) tem diversas semelhanças que tornam seus modos de vida, organização social e até posicionamentos políticos análogos.

A diversidade de características dos povos campesinos demonstra sua importância enquanto classe que reivindica seu papel na sociedade e seus direitos, e que diferente das concepções positivistas de classificação e homogeneização conceitual a riqueza de plurais camponeses se transforma em uma grande virtude (Bartra, 2011), é a diversidade de diferenças que tornam o campesinato tão rico e importante. Podemos identificar as semelhanças de cognições entre os diferentes campesinatos brasileiros ao analisar textos da pesquisadora Ellen F. Woortmann, que elucida a humanização da natureza como forma de cultivo camponesa ao dizer que “tem-se, portanto, como que uma ‘humanização' da natureza, uma concepção 'etno-ecológica holista'. O homem deve saber que a terra 'precisa ser bem tratada', do que resulta uma forma de reciprocidade positiva" (Woortmann, 2009: 120).

O cuidar e cultivar a terra para que essa em resposta lhes dê bons "frutos" é uma das características que causa semelhança entre os camponeses, no entanto, cada grupo camponês dependendo da região "sente" a terra de maneira diferente, terras "frias" e "quentes"; "gordas" ou "magras"; "fortes" ou "fracas". "A classificação das terras em "gordas" e "magras" pelos colonos teuto-brasileiros do Rio Grande do Sul equivale àquela dos camponeses sergipanos que as definem como 
fortes ou fracas." (Woortmann, 2009: 125). É válido entendermos que "para uma completa base material do campesinato, devemos acrescentar a pluralidade social, a multiplicidade étnica, a diversidade de clima, de paisagem, de história, de língua, de cultura etc." (Bartra, 2011: 74)

O Saber camponês passado entre as comunidades de geração em geração e influenciado por processos migratórios demonstra a importância do campesinato para a sociedade e que sofre constantes impactos sob influência do capitalismo, o diagnóstico de inevitável desaparecimento do campesinato pelo modo de produção capitalista é presente em diversos trabalhos desde a virada do século XIX.

Teodor Shanin (2005: 11) também contribui para esse questionamento ao afirmar que "os camponeses não são um modo de produção porque lhes falta a estrutura político-econômica relativamente autossuficiente, isto é, os sistemas mais significativos de exploração e apropriação do excedente tem sido, de modo geral, externos a eles". É necessário, para entender a perspectiva de Shanin, analisar tanto a pluralidade da "comunidade camponesa" quanto compreender que as relações de "exploração" presentes na estrutura do campesinato não se equivalem as relações exploratórias presentes na estrutura político-social em que os camponeses estão inseridos. São nítidos os impactos que o modo de produção capitalista provoca na sociedade camponesa por meio de políticas públicas totalmente parciais que em nada buscam suprir as necessidades demandadas por eles (camponeses). Logo, a perspectiva do campesinato como modo de produção existente em conformidade com o capitalismo teria mais como objetivo o de analisar a dissolução do campesinato frente ao avanço do capital, assim como afirmar que o campesinato persiste independentemente da existência ou não de camponeses o que na prática não se configura como lógico.

Ainda no que tange a classificação/enquadramento do campesinato como modo de produção ou em algum modo de produção foi massivamente difundido a relação e entrelaçamento do campesinato ao feudalismo, adiantamos que não será essa a perspectiva que será abordada neste trabalho, pois: a) essa perspectiva tende a reduzir o campesinato a única e exclusivamente resultado de um processo histórico e que não possui a capacidade de reprodução em outros espaços e sociedades, com isso sendo datado a esse processo histórico; b) tendência a exclusão de grupos familiares camponeses em espaços e sociedades em que não se teve o processo feudal (como é o caso o continente americano); e c) corroborando com o ponto de análise de Shanin (2005: 13) "tais procedimentos limitam, mais do que expandem, nossa compreensão da realidade social em suas complexidades e contradições". 


\section{AS POLÍTICAS PÚBLICAS E O AMA}

O MST surge no Pará na década de 1990, mas é somente com a implantação do segundo assentamento em Palmares que o MST se consolida no estado (Abe, 2004: 21) e a partir dessa consolidação foi possível se instalar no Pará diversos assentamentos, dentre estes está o AMA (Assentamento Mártires de Abril) no distrito administrativo de Mosqueiro em Belém, e suas atividades são de extrema importância para questão agrária e luta pela terra. A Lei de $n^{\circ} 4.504$, de 30 de novembro de 1964 (Lei No 4.504..., 1964), assegura o "conjunto de medidas que visem a promover melhor a distribuição da terra" o que legitima a luta pela posse da terra em que estão inseridos. Entender a relação entre o campo e a cidade como sistema integrado em Belém é de fundamental importância para auxiliar na ornamentação de projetos que atuem na melhoria socioeconômica e estrutural do próprio município, priorizando o desenvolvimento da agricultura familiar na região, em que, os camponeses que se reproduzem nas proximidades do centro urbano de Belém, além de melhorias econômicas para região, funcionam como um dos principais produtores de alimentos para a cidade.

De acordo com o Plano Amazônia Sustentável, projeto de política pública territorial que atua na área de influência da BR 163, instituído pelo Instituto Brasileiro do Meio Ambiente e dos Recursos Naturais Renováveis, "a sustentabilidade do desenvolvimento rural depende da regularização fundiária das terras públicas da Amazônia e da consolidação dos assentamentos rurais de reforma agrária, adequados à diversidade sociocultural, econômica e ambiental da região" (Casa Civil da Presidência da República, 2006: 60).

É importante elucidar que a relação campo/cidade é marcada pela disparidade de benefícios proporcionados para a cidade, como aponta Geipel e Neuburger (2004) "o poder econômico e sócio-político se concentra na cidade de forma que, muitas vezes, o espaço rural depende completamente das decisões dos atores urbanos". A extensão territorial brasileira e a incapacidade do poder público de gerir o espaço, resultam na necessidade de proporcionar políticas públicas capazes de suprir essas carências, pois de acordo com Peixoto (2009), as "propostas de espacialização das políticas oficiais, com concepções territoriais de desenvolvimento, apresentando-se como capazes de superar as limitações de ações setoriais desarticuladas". Como exemplo se tem o Projeto Casulo, criado pela Portaria Incra $n^{\circ} 321 / 1997$ e revogado pela Portaria Incra $n^{\circ} 414$, de 11 de julho de 2017, que tinha como um dos objetivos a tentativa de "municipalizar a reforma agrária" como explica Carla Lagoia umas das coordenadoras do AMA. O Projeto Casulo visava 
Implementar Projetos de Assentamento de Casulo em áreas disponíveis para reforma agrária, com prioridade de obtenção por meio da compra e venda, localizadas no entorno de núcleos urbanos com localização estratégica para assentamento de famílias, moradoras das periferias com a possibilidade de geração de emprego e renda, por meio de parcerias, de um lado, o Incra e, de outro, o poder público municipal. (Ministério do Desenvolvimento Agrário, 2013: 5).

Entendemos, porém, que essa tentativa de municipalizar (espacializar as políticas públicas), torna-se frustrada frente a desorganização político-social do estado como apresenta o documento Política Nacional de Ordenação do Território (PNOT)

As políticas ... se encontram desarticuladas entre si, só existindo alguma territorialidade ou espacialidade em poucos programas, sem, entretanto, refletir uma preocupação com aspectos conceituais de território e, por conseguinte, a tradução de políticas de gestão territorial (PNOT, 2006: 132).

O Assentamento Mártires de Abril é inserido no projeto e surge a partir de um acampamento pedagógico no centro de Belém - como resposta ao massacre de Eldorado do Carajás ocorrido em 1996 - formado pelo MST (Movimento dos Trabalhadores Rurais Sem Terra) em conjunto com a população residente da periferia da cidade. Ocupam posteriormente a fazenda Taba (Transportes Aéreos da Bacia Amazônica) e montam acampamento reivindicando a desapropriação da área, conquistando a terra em 2001, o campesinato se forma na região também em resposta a pressões de grupos hegemônicos que buscam manter a concentração fundiária e desigualdades sociais. A grande dificuldade de acordo com a Carla Lagoia - uma das militantes e coordenadora do AMA -, é "fixar o homem na terra" e para isso o poder público (municipal e federal) auxiliaria com a implementação e manutenção de infraestrutura nos lotes. Entre os programas inseridos no assentamento para o auxílio na produção foi o Programa Nacional de Fortalecimento da Agricultura Familiar (Pronaf), desenvolvido nos primeiros anos de ocupação nos lotes que, ainda de acordo com a dirigente, o período de 2001-2003 foi bastante danoso em decorrência da precariedade de orientação técnica das equipes representantes do estado e do próprio Pronaf.

O Pronaf ${ }^{2}$ tem por objetivo auxiliar em diversos pontos da produção agrícola em lotes familiares, tanto no custo da produção (Pronaf Custeio), como também com o Pronaf Mais Alimentos que possibilita a modernização no campo, dentre outros. O Pronaf Agroecologia era uma das linhas de crédito implementada no assentamento, que tinha por foco a manutenção técnica e o auxílio na produção

\footnotetext{
${ }^{2}$ Secretaria Especial de Agricultura Familiar e do Desenvolvimento Agrário. Recuperado de: http://www.mda.gov.br/sitemda/secretaria/saf-creditorural/linhas-de-cr\%C3\%A9dito
} 
agroecológica e orgânica dos produtores coletivos. No entanto, esses investimentos não obtiveram resultados positivos, demonstrando o olhar tecnicista e comercial do estado que está constantemente ligado a ideia de desenvolvimento, que, de acordo com Black.

Nesse caso, desenvolvimento, não obstante o uso a torto e a direito do impreciso adjetivo sustentável, significa exclusivamente crescimento das forças produtivas. Custe a quem custar. De fato, os grupos sociais percebem o desenvolvimento mais como dano do que como oportunidade de melhorar suas condições de vida (Peixoto, 2009: 68).

Essa perspectiva trouxe para o lote um grande problema de produção, resultando na perda de muitos produtores que desistiram do campo e retornaram para as periferias de Belém. Mesmo com a ineficiência do Pronaf nos primeiros anos do AMA, após muita luta e resistência dos agricultores, o assentamento resistiu e hoje consegue produzir de maneira coletiva diversas culturas. Outra estratégia que passou a se integrar à localidade, foram os Sistemas Agroflorestais ou SAFs, que visam o manejo de recursos naturais aliados ao cultivo agrícola e/ou pecuário no mesmo espaço (Montagnini, 1992), além do caráter ambiental que também possibilitou melhoria de renda e produção para os lotes em que foram implementadas.

Existem dois tipos de políticas econômicas que o estado intervém na agricultura, a primeira se refere a "política macroeconômica" e de acordo com Delgado (2009: 23) essa política é mais abrangente e que é "composta basicamente pela combinação das políticas fiscal, monetária, comercial e cambial" e afeta "direta e indiretamente" todos os setores da economia e por isso afeta também a agricultura e outros setores do meio rural. A segunda política se refere a "política setorial" e esta é formulada para "influenciar diretamente o comportamento econômico-social de um setor específico da economia nacional" (Delgado, 2009: 25) e quando direcionadas para a agricultura se subdivide em três tipos: agrícola, agrária e a política de diferenciada de desenvolvimento rural.

A política agrícola tem como principal foco de ação políticas de mercado (preços, regulação de mercado, entre outros) e políticas estruturais (infraestrutura, recursos naturais, etc.), regulariza, portanto, os preços e de que maneira se dá a comercialização de produtos agrícolas, além de condicionar as relações entre os diferentes setores com a agricultura. Quando se trata da política agrária, podemos definir que

tem como objetivo tradicional intervir na estrutura da propriedade e da posse da terra prevalecente no meio rural, através de sua transformação ou regularização nas regiões onde a terra já foi historicamente apropriada privadamente (política de reforma agrária) e de sua influência no processo de ocupação de novas terras consideradas - pelas agências estatais ou pelos atores privados - como de fronteira agrícola (política de colonização). (Delgado, 2009: 25-26) 
Com isso é possível afirmar que a política agrária é essencialmente estrutural, e devemos atentar para sua importância na América Latina, em que se tem a presença massiva de concentração fundiária e manutenção de desigualdades sociais no campo e nas cidades. $\mathrm{O}$ terceiro instrumento de intervenção do estado na agricultura são as chamadas "políticas ou programas diferenciados de desenvolvimento rural", que tem como foco os segmentos mais pauperizados do campesinato, além de assumir o papel de buscar a união entre as duas políticas anteriores (agrícola e agrária), atua por meio da mecanização desses espaços pauperizados e subsídios para seu desenvolvimento.

Pode-se traçar desde os anos 1950 diversos fatores que influenciaram as políticas públicas para diversos setores da economia e principalmente para o campo, o processo industrialização nessa década com a adoção do modelo de industrialização por substituição de importações que funcionava como estratégia para aproximar o Brasil dos países capitalistas internacionais, o estado passou a adotar diversas medidas que privilegiavam a implementação de industriais (perspectiva de referencial global ${ }^{3}$ ), logo na década de 1960 esse modelo encontra sérios problemas, com o aumento da demanda por alimentos e produtos agrícolas se inicia de uma crise de abastecimento de alimentos para as áreas urbanas. Assim, de acordo com Grisa e Schneider,

Desta crise, duas opções e "referenciais setoriais" aparecem na agenda pública. Reivindicada por acadêmicos (Caio Prado, Alberto Passos Guimarães, Ignácio Rangel e notadamente a vertente "cepalina estruturalista" representada por Celso Furtado), por políticos (nomeadamente o governo de João Goulart) e por movimentos sociais (Ligas Camponesas, União dos Lavradores e Trabalhadores Agrícolas do Brasil, Movimento dos Trabalhadores Sem Terra, Confederação Nacional dos Trabalhadores na Agricultura - Contag), uma destas opções clamava por um conjunto de reformas de base, dentre elas a reforma agrária, visando dinamizar o mercado interno. Contrapondo-se a esta opção e sustentada pelas elites agrárias, por acadêmicos vinculados a economistas da Universidade de São Paulo (principalmente Antônio Delfim Neto) e por militares que tomaram o governo federal, outro referencial setorial foi institucionalizado no Brasil, orientado pela modernização tecnológica da agricultura. (Grisa \& Schneider, 2014: 128-129)

A principal política pública territorial para o campo brasileiro é a política de reforma agrária que encontra diversas barreiras no Brasil, no entanto, com a redemocratização brasileira o debate acerca dessa política ressurgiu, é por meio do processo de assentamentos regularizados pelo INCRA, a partir de 1995, que

\footnotetext{
${ }^{3}$ Utilizaremos ao longo deste tópico, termos abordados por Muller (2005; 2008), Fouilleux (2003; 2011) e Grisa e Schneider (2014), como referencial global, referencial setorial e referencial de políticas públicas, que de acordo com os autores são os processos para construção de políticas públicas. Referencial global está ligado com o quadro geral de políticas públicas e sofre influencias delas para a construção de novas políticas.
} 
a reforma agrária se efetiva. Podemos analisar no gráfico 01 o número de assentamentos no período até 2006.

FIGURA 1: NÚMERO DE ASSENTAMENTOS AO LONGO DOS ANOS

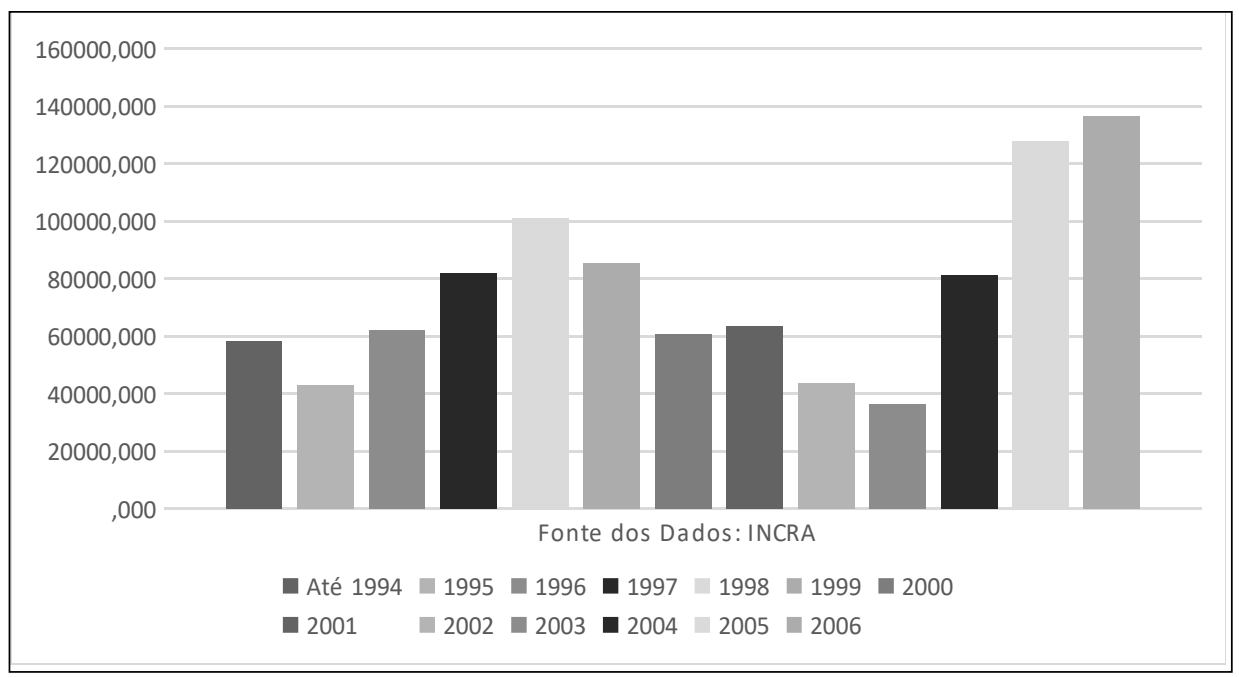

Fonte: Recuperado de http://www.incra.gov.br/pt/

Ao analisar esse gráfico, podemos perceber um aumento considerável de assentamentos criados durante o primeiro mandato do então presidente Luiz Inácio Lula da Silva, tendo o ano de 2006 como o mais expressivo no que tange a criação de assentamentos. De certa forma o posicionamento conciliador e amigável da época tende a frear os movimentos sociais do campo, que veem nesse governo a oportunidade para o suprimento dos problemas no campo. No entanto, temos nos anos seguintes um decréscimo no número de assentamentos chegando em um pouco mais de 22 mil em 2011 ainda durante o governo Lula. Já durante o governo da presidente Dilma Rousseff (2001-2016) esses números se estabilizam até o momento do impeachment em que temos o momento mais crítico se tratando da reforma agrária no brasil. 
FigURA 2: NÚMERO DE ASSENTAMENTOS AO LONGO DOS ANOS

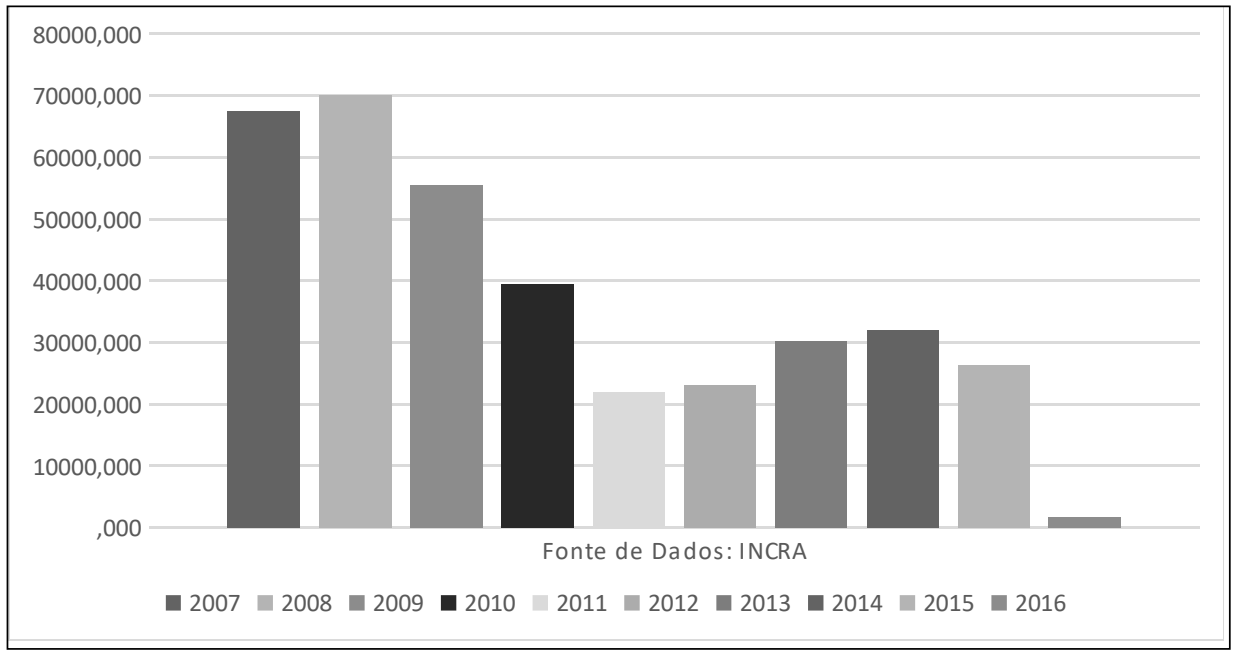

Fonte: Recuperado de http://www.incra.gov.br/pt/

Ao analisar os dados disponibilizados temos diversos problemas, Oliveira em 2007 já alertava para as contradições existentes nos dados disponibilizados pelo INCRA, em que afirma que,

já é do conhecimento público, a informação de que os dados divulgados precisam ser explicados, pois não correspondem a novos assentamentos. ... o que a mídia tem divulgado é que o "total de assentados atingiu 95\% da meta". Ou seja, fica parecendo que o MDA/Incra cumpriu a Meta 1 do II PNRA, que se refere ao assentamento das 400 mil famílias entre 2003 e 2006. Isto não é verdade, porque os dados referentes aos novos assentamentos em 2006 não foram divulgados separadamente daqueles referentes às demais metas.

... Assim, a mídia vai repetindo os números divulgados oficialmente e são eles que ficam na memória coletiva da população como se de fato o governo tivesse feito os assentamentos. (Oliveira, 2007 ${ }^{4}$ )

O que me parece ao analisar os dados é a nítida mudança de enfoque político com o passar dos anos, a reforma agraria está longe de ser finalizada, os conflitos no campo e concentração fundiária ainda produz desigualdades na sociedade. A substituição de enfoque se concretiza desde 2016, em que se altera a política de criação de assentamentos e é substituída pela de titulação de terras. Os motivos para a substituição entre essas políticas é a tentativa do estado de retirar suas obrigações com a reforma agrária, a criação de assentamentos traz respon-

4 Texto Recuperado de: https://reporterbrasil.org.br/2007/02/os-numeros-da-reforma-agraria-dogoverno-lula/ 
sabilidades para o estado em criar infraestrutura, escola, disponibilizar investimentos, etc., o que com a política de titulação de terras essa responsabilidade não existe. Nos anos de 2016, 2017 e 2018 temos os menores números de assentamentos criados pela reforma agrária $(1.686,1.195,7.189$ respectivamente de acordo com dados do INCRA), e temos em 2017 a imposição do "titulômetro" como ficou conhecimento o sistema de premiação dentro do INCRA para as superintendências regionais que mais derem títulos individuais de propriedade de terra, resultando em uma precariedade na reforma agrária e como alertava Oliveira (2007) "os grandes derrotados foram os camponeses em geral e com eles uma parte da sociedade brasileira, que permanece na esperança de que um dia, a dívida social da reforma agrária seja verdadeiramente paga".

A partir dos anos 2000 temos uma nova configuração de políticas públicas, nesse momento o referencial de política pública passa a ser a segurança alimentar e sustentabilidade ambiental. Iniciados com o programa Fome Zero, a agricultura familiar camponesa teve nova função na relação campo-cidade, em que o Estado identificou diversos problemas como o valor dos alimentos básicos que não eram condizentes com o poder aquisitivo da população, havendo assim a necessidade de mudança na produção, principalmente na agricultura familiar e no consumo. Isso desencadeou o surgimento do PAA (Programa de Aquisição de Alimentos) em 2003, cujo objetivo é "articular a compra de produtos da agricultura familiar com ações de segurança alimentar (distribuição de alimentos) para a população em vulnerabilidade social" (Grisa \& Schneider, 2014: 139).

A luta pela terra no Pará é marcada pela resistência e pelo sangue dos mortos pelo conflito no campo, de modo que um dos marcos na luta pela terra foi o massacre de Eldorado dos Carajás em 17 de abril de 1996, quando dezenove sem-terra foram mortos pela Polícia Militar do Estado do Pará em um acampamento próximo à fazenda Macaxeira. Como resultado do massacre, o MST organizou diversas manifestações e acampamentos com o intuito de cobrar respostas do poder público e aumentar a atuação do movimento. Fernandes (2000) nos afirma que,

Assim, os sem-terra continuam ocupando a terra, pois sabem que a reforma agrária só será efetiva se eles estiverem organizados, e dessa forma reivindicarem justiça para seus mortos, lutando contra a impunidade e a violência. O massacre de Eldorado dos Carajás é mais uma marca de sangue na história desses 500 anos latifúndio e de luta pela terra. (2000: 212)

Na cidade que dá as costas ao rio e em frente ao local onde anos depois seria erguida a Coluna da Infâmia, no ano de 1999, o MST organiza um acampamento pedagógico na capital paraense com a população residente da periferia da cidade (e de cidades próximas) iniciando um trabalho de base (Abe, 2004; Silva, 
2016) em que consistia na transformação a Praça da Leitura, em São Brás, em uma experiência de acampamento na terra. É importante a diferenciação entre assentamento e acampamento, para Rocha (2015: 41) o acampamento é formado quando se ocupa um latifúndio e até se ter a "[...] posse legal da terra, enquanto o assentamento é quando se legaliza a posse da terra e se conquistam os créditos para a produção e moradias; é o resultado dos meses ou anos de lutas no acampamento".

A população que se aproximou do movimento e passou a integrar o acampamento pedagógico eram pessoas que de certa forma não estavam aguentando a vida precária nas periferias de Belém (desemprego, violência urbana, etc.), e com isso buscavam um lugar para viver e trabalhar e para Bringel (2001: 39) "a aproximação do MST às capitais representa uma saída das condições de vida precária das cidades e um retorno às origens da terra, reterritorializando esses indivíduos como trabalhadores rurais". Contraditoriamente da perspectiva de que o campo se rende perante o urbano sendo irrefutável e irreversível o camponês ser implementado a cidade ou ao capital - como abordado no anteriormente neste trabalho -, temos em Belém um movimento de "êxodo urbano",

No caso do Acampamento Mártires de Abril, [...] estabelece uma alternativa de retorno ao campo, só que em uma área urbana na sua zona rural. Da repulsão (entendida como situações de vida responsável pela insatisfação do local de origem) anterior, vinda principalmente da concentração de terra no campo, produzindo o êxodo rural. É o retorno, a partir de uma estratégia de um movimento social de massa - MST, para a atração (entendida como os atributos dos locais que se tornam atraentes) ao campo só que agora representado por uma zona rural em uma ilha pertencente ao Município de Belém. Uma espécie de "êxodo urbano" só que de uma zona urbana para uma zona rural, isso tudo dentro do espaço urbano (Bringel, 2001: 38).

As famílias que participaram do acampamento pedagógico se instalaram no distrito administrativo de Mosqueiro, localizado a $70 \mathrm{~km}$ de distância do centro de Belém. A Ilha de Mosqueiro teve uma ligação com o centro de Belém por meio da construção da ponte Sebastião de Oliveira nos anos 70, o contato com a ilha era somente possível anteriormente pela via fluvial. Mosqueiro é dos pontos turísticos durante o período de férias, Abe nos elucida as características da ilha e que sofre "a influência das marés, por isso possuem ondas, tornando-as semelhantes às praias de oceano, embora sejam praias de rio, o que se constitui em atrativo para os banhistas" (Abe, 2004: 78). Nesse ponto, Mosqueiro exerce diversas funções em relação a Belém continental: a) o de laser, principalmente durante dois meses no ano; b) local de residência de parte da população que se transferiu da periferia de Belém e de outras cidades; c) área que deve ser preservada; e d) campo de resistência e de produção de camponeses por meio da permanência em assentamentos rurais da reforma agrária. 
É durante o período de férias que os investimentos em saúde e segurança são implementados em mosqueiro, com o foco de atrai os "veranistas" para as praias do distrito, movimentando a economia da Ilha e possibilitando a parte dos assentados a buscar alternativas para aumentar sua renda por meio do trabalho assalariado ou alternativo. A população residente da Ilha de Mosqueiro mais do que duplicou em 40 anos, indo de 14.460 mil habitantes em 1980 a 33.232 mil habitantes em 2010, a estimativa é de 50 mil habitantes atualmente (IBGE). O crescimento populacional da ilha ocorre devido ao processo de abertura da rodovia Meira Filho em 1965 e se intensifica com a construção da Ponte Sebastião de Oliveira em 1976, de acordo com Ferreira (2012) nos últimos 30 anos mosqueiro se reconfigura, e as moradias temporárias passam a ser moradias fixas, além de aumentar a presença de assentamentos e ocupações nas áreas da ilha. Belém possui cerca de dez assentamentos rurais, dentre eles, temos dois PCA (Projeto de Assentamento Casulo), um PA (Projeto de Assentamento Federal) e sete PAE (Projeto de Assentamento Agroextrativista), como podemos perceber na Tabela 1.

\section{TABela 1: Assentamentos EM BELÉM}

\begin{tabular}{l|l|c|c|c|c}
\multicolumn{1}{c|}{ Assentamento } & \multicolumn{1}{c}{$\begin{array}{c}\text { Área } \\
\text { de Belém }\end{array}$} & Cap. & $\begin{array}{c}\text { Fam. } \\
\text { Assenta- } \\
\text { das }\end{array}$ & $\begin{array}{c}\text { Data } \\
\text { de Criação }\end{array}$ & Área (ha) \\
\hline $\begin{array}{l}\text { PCA MÁRTIRES } \\
\text { DE ABRIL }\end{array}$ & $\begin{array}{c}\text { Ilha } \\
\text { de Mosqueiro }\end{array}$ & 95 & 94 & $30 / 10 / 2001$ & 408,0000 \\
\hline $\begin{array}{l}\text { PCA ELIZABETH } \\
\text { TEIXEIRA }\end{array}$ & $\begin{array}{c}\text { Ilha } \\
\text { de Mosqueiro }\end{array}$ & 27 & 27 & $23 / 09 / 2004$ & 71,7372 \\
\hline $\begin{array}{l}\text { PA PAULO } \\
\text { FONTELES }\end{array}$ & $\begin{array}{c}\text { Ilha de } \\
\text { Mosqueiro }\end{array}$ & 60 & 59 & $13 / 07 / 2006$ & 848,5102 \\
\hline $\begin{array}{l}\text { PAE ILHA } \\
\text { GRANDE BELÉM }\end{array}$ & $\begin{array}{c}\text { Ilha Paulo } \\
\text { da Cunha }\end{array}$ & 99 & 99 & $28 / 09 / 2006$ & 922,8357 \\
\hline $\begin{array}{l}\text { PAE ILHA } \\
\text { JUTUBA }\end{array}$ & Ilha Jutuba & 73 & 72 & $28 / 09 / 2006$ & 513,5044 \\
\hline $\begin{array}{l}\text { PAE ILHA } \\
\text { MURUTUCU }\end{array}$ & Ilha Murutucu & 144 & 121 & $28 / 09 / 2006$ & 877,4825 \\
\hline $\begin{array}{l}\text { PAE ILHA } \\
\text { PAQUETÁ }\end{array}$ & Ilha Paquetá & 108 & 103 & $28 / 09 / 2006$ & 802,2588 \\
\hline $\begin{array}{l}\text { PAE ILHA } \\
\text { DO COMBU }\end{array}$ & Ilha do Combu & 230 & 205 & $07 / 11 / 2006$ & 1508,7929 \\
\hline $\begin{array}{l}\text { PAE COMPLEXO } \\
\text { MARACUJÁ }\end{array}$ & $\begin{array}{c}\text { Ilha } \\
\text { do Maracujá }\end{array}$ & 150 & 143 & $07 / 11 / 2008$ & 824,8050 \\
\hline $\begin{array}{l}\text { PAE ILHA NOVA } \\
\text { Total }\end{array}$ & Ilha Nova & 50 & 28 & $09 / 09 / 2009$ & 273,8878 \\
\hline
\end{tabular}

Fonte: Recuperado de http://www.incra.gov.br/pt/ 
Entre os períodos analisados anteriormente temos a criação em 1997 do Projeto Casulo, que tem como um dos objetivos a municipalização da reforma agrária, é um programa de parceria entre o Governo Federal com as Prefeituras Municipais, criado pela Portaria do INCRA de $n^{\text {o }} 321 / 1997$ e que funciona em parceria ao Programa Brasil Sem Miséria (PBSM), a estratégia do programa é bem clara e afeta em demasiado as relações campo/cidade nos munícios em que é implantado. Um dos objetivos do Projeto Casulo é o de implementar assentamentos em áreas ao entorno da zona urbana dos municípios com o intuito de gerar empregos e renda para as famílias,

1. Implementar Projetos de Assentamento de Casulo em áreas disponíveis para reforma agrária, com prioridade de obtenção por meio da compra e venda, localizadas no entorno de núcleos urbanos com localização estratégica para assentamento de famílias, moradoras das periferias com a possibilidade de geração de emprego e renda, por meio de parcerias, de um lado, o Incra e, de outro, o poder público municipal.

2. Definir a "rota" para implantação de Projetos Casulos, próximos a cidades, bem como naquelas que necessitem dar acesso as populações existentes na periferia dos núcleos urbanos, na possibilidade de geração de emprego e renda. (Ministério do Desenvolvimento Agrário, 2013: 05)

O Assentamento Mártires de Abril foi o primeiro no município de Belém a ser implementado no projeto Casulo com o arrendamento da antiga fazenda de Transportes Aéreos da Bacia Amazônica (TABA), a legitimação da terra para ser criado o projeto de assentamento Casulo foi efetivada em 30 de outubro de 2001 , a criação e integração do AMA no projeto Casulo se passou de um período de ocupação extremamente conturbado, em que no início do processo de ocupação (1999) alguns pistoleiros a mando do ex-gerente da fazenda ameaçam e executam diversas tentativas de homicídio ao assentados, resultando em quatro camponeses gravemente feridos (Abe, 2004), com a resistência camponesa, quatro despejos (realizados pela Polícia Militar do Pará e com o quantitativo de mais de 400 PMs e cinco ocupações e após a ocupação do INCRA em 2000 por 200 famílias, alguns acordos são tratados, dentre eles a "garantia de que a Fazenda TABA não viria a sofre novos despejos.

De acordo com um dos assentados durante diversos diálogos, o camponês e militante elucidou que o atual prefeito do município de Belém "não conhecia que tinha assentamento em Mosqueiro, né?! E nós 'têm' três assentamentos. Aí a política pública fica desse jeito, ficamos na verdade abandonados" (Entrevista

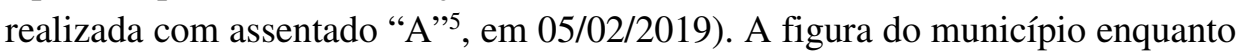

\footnotetext{
${ }^{5}$ Utilizamos outros termos para designar os diferentes assentados que foram entrevistados com o intuito de preservar suas identidades conforme solicitado e conversado antes do início da pesquisa.
} 
apoio que deveria ser efetiva no projeto Casulo não ocorre, em pesquisas realizadas de agosto de 2018 a janeiro de 2019 entre os órgãos responsáveis pela transparência de investimentos em Belém, mais especificamente o Tribunal de Conta dos Municípios (TCM), em conversa com um dos funcionários do órgão em 22 de novembro de 2018, foi abordado a crítica dos funcionários perante a falta de transparência de investimentos destinado a políticas públicas em Belém, "os dados não são claros, temos somente o valor sintético e de quanto é destinado para cada área" (Entrevista realizada com servidor do TCM em 22/11/2018). Os investimentos municipais não são transparentes e aliado ao desconhecimento da prefeitura para com a existência de assentamentos nas ilhas de Belém (somente assentamentos temos o total de 10) demonstra o cuidado que o poder público tem em relação ao povo do campo. É importante elucidar que recentemente o AMA contou com um investimento público do Instituto de Desenvolvimento Florestal e da Biodiversidade do Estado do Pará (Ideflor-bio), em agosto de 2017, que tinha como objetivo a criação de um viveiro de mudas.

De acordo com os assentados desde a regulamentação do assentamento e inserção no projeto Casulo, esta é a primeira "política pública" inserida no AMA. O viveiro conta com diferentes espécies de muda (ingá, muruci, cupuaçu, etc.), o interessante é que a produção agroecológica está presente em todos os passos da produção na terra, do plantio a colheita, em que as mulheres e homens exercem papéis de respeito mútuo e companheirismo.

De acordo com Carla Lagoia "depois que tu conquistas a terra, a maior luta é pra tu permaneceres naquela terra, naquele território [...] é um processo de luta permanente" (Entrevista realizada com Carla Lagoia, em 04/07/2018), dentre o processo permanente de luta nos fronts, para o camponês o mais importante é continuar na terra, produzindo em seu território, como levantado anteriormente, a proletarização da mão-de-obra camponesa como alternativa para manter a sua reprodução no campo (Bartra, 2011), essa perspectiva está presente no AMA em que pelo menos um membro de cada uma das 94 famílias proletarizam parte de sua força de trabalho na zona urbana da Ilha de Mosqueiro e/ou no centro de Belém. Esses camponeses trabalham em ocupações diversas, "alguns trabalham nas praias, mas grande parte trabalha como pedreiro ou ajudante de pedreiro, saem de Mosqueiro para Belém todos os dias" (Entrevista realizada com assentada "B" em 05/02/2019), com isso, grande parte passa a semana em Belém como ajudante de pedreiro e volta para ajudar a família no cultivo do solo, em poucos casos o assentado fica alguns meses trabalhando na parte continental de Belém e em seguida retorna ao campo, quando o camponês que vendeu sua mão-de-obra 
retorna para o campo este passa auxiliar no cultivo e participar do cotidiano camponês, sem dessa forma perder a sua identidade.

Como um dos passos para a implantação do Projeto Casulo era a construção de uma escola que atendesse os assentados e a comunidade residente de mosqueiro, o objetivo era a construção dessa escola dentro do território do assentamento, no entanto com a mudança de prefeito, entre o Edmilson Rodrigues e o primeiro mandato do Duciomar Costa, temos uma alteração do projeto inicial e a transferência da escola para uma região afastada do assentamento e até da zona urbana de Mosqueiro, a decisão tinha como motivos a falta de crianças no assentamento, porém de acordo com Carla Lagoia, o AMA possui entre 100-130 crianças com a idade de zero a doze anos, para os assentados essa mudança de espaços tem como objetivo um "boicote" e afastar os assentados para não manterem contato com a escola. Para Lagoia torna-se complicado não ter uma escola do campo para as crianças do assentamento, a escola tem que constituir uma identidade camponesa, "como é do campo se não constrói a identidade do campo?" (Entrevista realizada com Carla Lagoia em 05/02/2019). Se a educação não possibilita a reflexão e valorização do campesinato e da natureza como podemos afirmar que o ato de educar é efetivo?

O enfoque do projeto Casulo está na produção agroecológica e principalmente hortifrutigranjeiro em decorrência da dimensão de cada lote de terra (cerca de 4 ha por lote). De acordo com os assentados, a CODEM (Companhia de Desenvolvimento e Administração da Área Metropolitana de Belém) durante os primeiros anos da instauração do AMA e com o intuito de dar continuidade ao projeto Casulo forneceu um grupo de agrônomos para que coordenassem e adequassem a produção dos lotes de acordo com cada especificidade, no entanto, foi implementado o cultivo de frangos brancos, e de árvores frutíferas (açaí, cupuaçu, entre outros). Os investimentos oriundos do Pronaf tiveram como enfoque o auxílio nesta produção, o relato de uma das assentadas e que a produção de frangos brancos não encontrou mercado e que,

todo investimento que veio do Pronaf foi pra alimentação dos frangos e para outros gastos, não houve retorno [...] depois de um tempo os frangos por serem muito sensíveis começaram a ter uma doença, e todos foram morrendo aos poucos, vieram técnicos e levaram as cabeças dos frangos pra estudar e até hoje não trouxeram respostas, só ficou a dívida do Pronaf. (Entrevista realizada com assentada "C" em 05/02/2019)

O Pronaf é uma das políticas agrícolas mais expressiva no país, como abordado anteriormente. O programa tem como objetivo o fortalecimento da agricultura familiar, no entanto, na prática, se configura como uma política de endivi- 
damento que não leva em consideração a peculiaridade de cada localidade e nem de cada camponês. De acordo com a vivência do campesinato que resiste no AMA, seria mais adequado o cultivo e manejo de galinhas e frangos caipiras por serem mais fortes e resistentes a diversidade de situações dos lotes, porém a particularidade e saberia camponesa foi negligenciada pelo poder público gerando conflitos entre a percepção do que é importante para a manutenção dos interesses capitalistas e a necessidade dos camponeses. Muitos assentados no AMA pensaram em desistir da vida no campo em decorrência da dívida oriunda do Pronaf, "muitos assentados entraram em depressão, até hoje a maioria luta para poder entrar em acordo com o banco" (Entrevista realizada com assentado "A" no dia 05/02/2019). Para o camponês restam as dívidas enquanto para os ruralistas perdões estatais ${ }^{6}$.

É importante entendermos o regime de parceria proposto pelo projeto $\mathrm{Ca}$ sulo entre prefeitura e o governo federal, e de que forma este regime impactou nas relações campo-cidade e qual a interferência e desafios quando relacionado ao Plano Diretor Urbano de Belém. Para isso devemos entender que o projeto Casulo privilegiou a obtenção de terras por meio da compra/venda, e não por meio somente da desapropriação de terra improdutivas.

Implementar Projetos de Assentamento de Casulo em áreas disponíveis para reforma agrária, com prioridade de obtenção por meio da compra e venda, localizadas no entorno de núcleos urbanos com localização estratégica para assentamento de famílias, moradoras das periferias com a possibilidade de geração de emprego e renda, por meio de parcerias, de um lado, o Incra e, de outro, o poder público municipal. (Ministério do Desenvolvimento Agrário, 2013: 05)

Como abordado anteriormente, o governo federal por meio do Instituto Nacional de Colonização e Reforma Agrária (INCRA) se responsabiliza pela titulação da terra, e a prefeitura municipal, no caso de Belém por intermédio da CODEM, teria como papel o aparato de maquinário e de técnicos para auxiliar nos assentamentos, com isso, os projetos buscavam a implementação da reforma agrária na região por meio de desapropriações e regulamentação de assentamentos. De acordo com dados levantados pela coordenação do INCRA, até 2018 foram desapropriados 954 imóveis somente na região Norte ${ }^{7}$.

\footnotetext{
${ }^{6}$ Em 2018 ocorreu a pressão da bancada e dos ruralistas para a anistia da dívida com a União de 17 bilhões de reais, o processo havia sido discutido pelo Presidente Jair Bolsonaro no perdão da dívida. ${ }^{7}$ A Região Norte brasileira corresponde a SR-01/Pará, SR-14/Acre, SR-15/Amazonas, SR-17/Rondônia, SR-21/Amapá, SR-25/Roraima, SR-26/Tocantins, SR-27/Sul do Pará e SR-30/Oeste do Pará.
} 
TABEla 2: NúMEROS DA REFORMa AgRÁRIA ATÉ 2018.

\begin{tabular}{l|c|c|c|c}
\multicolumn{1}{c|}{$\begin{array}{c}\text { Superintendência } \\
\text { Regional }\end{array}$} & $\begin{array}{c}\text { Decretos } \\
\text { Desapropriação }\end{array}$ & Projetos & Área (ha) & $\begin{array}{c}\text { Famílias } \\
\text { Assentadas }\end{array}$ \\
\hline SR-01/Pará & 77 & 400 & 4.116 .271 & 143.680 \\
\hline SR-14/Acre & 84 & 161 & 5.602 .760 & 40.325 \\
\hline SR-15/Amazonas & 5 & 146 & 27.771 .820 & 64.480 \\
\hline SR-17/Rondônia & 65 & 224 & 6.227 .101 & 46.586 \\
\hline SR-21/Amapá & 4 & 53 & 2.168 .588 & 20.523 \\
\hline SR-25/Roraima & - & 66 & 1.444 .701 & 29.969 \\
\hline SR-26/Tocantins & 371 & 382 & 1.245 .484 & 44.254 \\
\hline SR-27/Sul do Pará & 332 & 515 & 4.610 .711 & 99.259 \\
\hline SR-30/Oeste do Pará & 16 & 230 & 14.581 .730 & 63.471 \\
\hline Total Norte & 954 & 2.187 & 67.769 .166 & 552.547
\end{tabular}

Fonte: Recuperado de http://www.incra.gov.br/pt/

Ainda sobre o regime de parceria proposto pelo projeto Casulo é importante refletirmos sobre a perspectiva do território camponês que é pautado como foco da ação do projeto, e que,

A despeito das intenções expressas em tantos documentos oficiais que pregam a integração das políticas públicas, estas ainda são concebidas e praticadas de forma isolada, sem que haja entre elas uma interlocução que permita a conjugação de meios e objetivos. (Peixoto, 2009: 68-69)

De acordo com o Assentado B, o INCRA não executou seu papel, pois a terra que primeiramente seria destinada ao AMA não foi arrendada, resultando na ocupação da Fazenda TABA pelo MST, local onde atualmente o AMA está assentado, nesse ponto a ocupação e luta pela terra (o território) e sua legitimação para o camponês é em decorrência dos movimentos socioterritoriais do campo, "o MST faz a divisão e ocupação de terras improdutivas, que deveria ser o papel deles (INCRA) e ainda não nos dão apoio com políticas públicas" (Entrevista realizada com assentada "B" em 05/02/2019). Os dados que são apresentados como diagnósticos pelo INCRA não transparecem a luta e dificuldades para o camponês, o maior desafio para o camponês é permanecer na terra conquistada, dos 104 (cento e quatro) assentados no AMA que são cadastrados no INCRA, somente oito foram desligados do cadastro, a comunidade assentada e o MST se

\footnotetext{
${ }^{8}$ Área destinada para a implantação dos projetos o que se diferem das áreas que foram desapropriadas.
} 
unem para que consigam desenvolver suas atividades e poder se reproduzir enquanto camponeses.

De acordo com o levantamento do Ministério do Desenvolvimento Agrário (MDA), a agricultura familiar camponesa é a oitava maior produtora de alimentos do mundo, atingindo o faturamento anual com produção de alimentos de 55,2 bilhões de dólares e de acordo com o Censo Agropecuário do IBGE a agricultura familiar camponesa está presente como base da economia de $90 \%$ dos municípios brasileiros com até 20 mil habitantes. A agricultura familiar é responsável por cerca de $70 \%$ do alimento presente na mesa da população, de acordo com Governo do Brasil (2018),

A agricultura familiar ainda produz $70 \%$ do feijão nacional, $34 \%$ do arroz, $87 \%$ da mandioca, $46 \%$ do milho, $38 \%$ do café e $21 \%$ do trigo. O setor também é responsável por $60 \%$ da produção de leite e por $59 \%$ do rebanho suíno, $50 \%$ das aves e $30 \%$ dos bovinos. (Governo do Brasil, 2018)

É importante perceber, que ocorre um intenso processo de retirada da vegetação nativa da região Amazônica em detrimento de monoculturas extensivas para a comercialização, como é o caso da soja e do dendê no espaço Amazônico que se mostram extremamente prejudiciais para o solo e ameaçam a agricultura familiar, pois como afirma Winnie (2013)

mostrando que $70 \%$ a $75 \%$ dos alimentos básicos da mesa do(a) brasileiro(a) vêm da agricultura familiar, mesmo ocupando uma área extremamente limitada se comparada às terras ocupadas pelo agronegócio. Aponta ainda que a lógica do agronegócio é a de que "o Brasil já produz muitos alimentos e pode produzir muito mais". Esse é um pensamento equivocado, pois, na realidade, a preocupação é incorporar o(a) agricultor(a) dentro do negócio do dendê e [...] têm pouco tempo e espaço para produzir seus próprios alimentos e também para o mercado local (Winnie, 2013: 4).

O camponês assentado que reproduz no AMA não é reconhecido pela prefeitura, para D. Maria (presente no AMA desde e o processo de ocupação) "se para o prefeito nós não produzimos para eles, pra população, então deveríamos parar de plantar mesmo e deixar eles sem nada" (Entrevista realizada em 05/02/2019). As ilhas do município fazem parte do território de Belém, no entanto, a tentativa de homogeneização forçada por meio de políticas públicas e planejamentos que não se adequam a realidade insular resultam na precarização da vida, tanto do campo quanto da cidade (as ilhas de Belém são predominantemente rurais de acordo com dados referentes ao Anuário 2011 e 2012 da prefeitura). A reforma agrária nos números, como mostrados anteriormente, demonstram que está sendo efetiva no Brasil, e principalmente na região norte que concentra mais da metade de hectares dos projetos destinados a essa política pública territorial. 
Porém, os números não elucidam a luta e a precariedade de investimentos destinados ao camponês, a partir desta perspectiva, é de suma importância para os pesquisadores do campo (e áreas afins) estudarem a resistência camponesa e os desafios das políticas públicas territoriais para o campo, com o intuito de diminuir as desigualdades sociais e da divisão territorial do trabalho, além de proporcionar um estudo acerca dos impactos que essas políticas causam na vida do campesinato.

\section{CONCLUSÃO}

Deste modo, é imprescindível que analisemos as políticas públicas para o campo como fundamentais para o crescimento e fortalecimento dessa importante produção para a sociedade, tendo em vista que de acordo com o portal do Governo do Brasil (2018), a agricultura familiar no país é a $8^{\circ}$ maior produtora de alimentos em todo o mundo com o faturamento de US\$ 55,2 bilhões e compõem o principal produtor de alimentos para a população, desmistificando a perspectiva levantada por grande parte dos empresários rurais e poder hegemônico de que o campesinato não produz ou gera economia. Ademais, o constante descaso do Governo brasileiro para com os produtores familiares, chegando ao corte de orçamento em 35,4\% para o ano de 2018, segundo dados levantados pelo portal de notícias do G1 (Martello, 2017) a queda é de 3,44 bilhões de reais em investimentos, o que representa o extremo desleixo no setor - o agro que não é "pop" em detrimento de investimentos direcionados ao agronegócio que possui foco para o mercado externo, ou seja, existe uma contradição entre o percentual de produção de produtos agrícolas para a população (70\% à 70\%) e a redução de investimentos do poder público na agricultura familiar. É sintomático a atual situação de desinteresse do Estado frente a política de reforma agrária, em que pouco se investe na pequena produção. Hoje o agricultor familiar enfrenta dois grandes vilões no campo: o inimigo histórico do latifundiário e o inimigo do capital estrangeiro em busca de terras para o plantio do biocombustível.

A política pública territorial de reforma agrária está longe de encontrar seu melhor desfecho no Brasil, de acordo com a Tabela 01 podemos perceber que na região Norte foram disponibilizados e regulamentados 67.769 .166 ha para projetos de reforma agrária até o ano de 2018, no panorama nacional totalizam 89.446.640 ha, os números estão longe de serem o essencial, de acordo com oCenso Agro de 2017 são cerca de 350 milhões de ha a área de estabelecimentos agropecuários (aumento de 5\% em relação ao censo de 2006), em que cerca de $70 \%$ dos estabelecimentos têm área entre 1 a 50 hectares, ou seja, muitos com 
pouca terra, dados levantados no Atlas da Terra Brasil 2015, organizados pelo CNPq/USP, apontam que 175,9 milhões de hectares no Brasil são improdutivos. Nesse embate de lados, o latifundiário vence a disputa.

O caso específico do Assentamento Mártires de Abril demonstra na prática a falta de investimentos para o pequeno produtor rural na Amazônia, não existe manutenção dos investimentos públicos e mesmo com todas as dificuldades o campesinato resiste e continua a sua produção. O AMA é o retrato explicito de um país que cresce ao se apoiar na agricultura familiar camponesa e investe no agronegócio para lucrar. Se de um lado, temos o campesinato que produz sem utilização de agrotóxicos e mão de obra familiar, temos, no outro, a perigosa produção agroindustrial com uma produção cada vez mais dominada pelo agrotóxico. O projeto Casulo não se manteve enquanto investimento para a região estudada, no entanto serviu como propulsor para uma tentativa de municipalização da Reforma Agrária, um projeto esquecido pela política de desenvolvimento regional, um "casulo" que não desabrochou.

\section{REFERÊNCIAS BIBLIOGRÁFICAS}

Abe, M. N. (2004). Mártires de Abril: o MST semeando a utopia camponesa (tese de mestrado). Belém, Brasil: Universidade Federal do Pará.

Abramovay, R. (1992). Paradigmas do capitalismo agrário em questão. São Paulo, Brasil: Hucitec; ANPOCS.

Bartra, A. (2011). Os Novos Camponeses: leituras a partir do México profundo. São Paulo, Brasil: Cultura Acadêmica; Cátedra Unesco de Educação do Campo e Desenvolvimento Rural.

Bringel, F. O. (2001). Do Rural ao Urbano: Territorialidade do MST em Área Metropolitana. Caso do Acampamento Mártires de Abril em Mosqueiro (trabalho de conclusão de curso). Universidade Federal do Pará.

Casa Civil da Presidência da República. (2006). Plano de Desenvolvimento Regional Sustentável para a Área de Influência da Rodovia BR-163 Cuiabá-Santarém. Brasília, Brasil: Grupo de Trabalho Interministerial.

Chizzotti, A. (2003). A pesquisa qualitativa em ciências humanas e sociais: evolução e desafios. Revista Portuguesa de Educação, 16(2), pp. 221-236.

Delgado, N. G. (2009). Política econômica, ajuste externo e agricultura. In S. Leite (Ed.), Políticas Públicas e Agricultura no Brasil (pp. 17-54). Porto Alegre, Brasil: Editora da UFRGS.

Fernandes, B. M. (2000) Formação e territorialização do MST no Pará. Cultura Vozes, 94(2). pp. 3-18.

Fernandes, B. M. (2005). Movimentos socioterritoriais e movimentos socioespaciais: contribuição teórica para uma leitura geográfica dos movimentos sociais. Revista Nera. Presidente Prudente. 8(6). pp. $14-34$. 
Fernandes, B. M. (2008). Entrando nos territórios do Território. In E. T. Paulino, J. E. Fabrini (Eds.), Campesinato e territórios em disputa (1 ${ }^{\mathrm{a}}$ ed., pp. 273-301). São Paulo, Brasil: Expressão Popular.

Ferreira, S. B. (2012). A Expansão dos Assentamentos Residenciais na Ilha de Mosqueiro: uma oportunidade de dispersão urbana no espaço metropolitano de Belém (PA) (tese de mestrado). Belém, Brasil: Universidade Federal do Pará.

Fouilleux, È. (2003). La politique agricole commune et ses réformes: une politique à l'épreuve de la globalisation. Paris, França: L'Harmattan.

Fouilleux, È. (2011). Analisar a mudança: políticas públicas e debates num sistema em diferentes níveis de governança. Estudos sociedade e agricultura, 19(1), pp. 88-125.

Geipel, F., \& Neuburger, M. (2004). As relações campo - cidade na periferia Amazônica: exemplos de Mato Grosso e Tocantins. II Seminário Internacional sobre Desenvolvimento Regional (Santa Cruz do Sul, RS, Brasil, 28/09 a 01/10 de 2004). https://www.unisc.br/site/sidr/2004/conferencias/01.pdf

Grisa, C., \& Scheneider, S. (2014). Três gerações de políticas públicas para a agricultura familiar e formas de interação entre sociedade e estado no Brasil. Revista de economia e sociologia rural, (52), pp. 125-146. https://doi.org/10.1590/S0103-20032014000600007

Governo do Brasil (2018, junho 8). Agricultura familiar do Brasil é a $8^{a}$ maior produtora de alimentos no mundo. http://www.brasil.gov.br/editoria/economia-e-financas/2018/06/agricultura-familiar-brasileira-e-a-8a-maior-produtora-de-alimentos-do-mundo

Instituto Nacional de Colonização e Reforma Agrária (2017). Projetos de Reforma Agrária Conforme Fases de Implementação. Brasília, Brasil: Ministério do Desenvolvimento Agrário.

Lakatos, E. V., \& Marconi, M. A. (2003). Metodologia do trabalho científico: procedimentos básicos, pesquisa bibliográfica, projeto e relatório, publicações e trabalhos científicos. São Paulo, Brasil: Atlas.

Lefebvre, H. (1978). De lo rural a lo urbano. Barcelona, Espanha: Península.

Lei $N^{\circ}$ 4.504, de 30 de Novembro de 1964 (1964, Novembro 30). Câmara Dos Deputados Centro de Documentação e Informação. http://www2.camara.leg.br/legin/fed/lei/1960-1969/lei4504-30-novembro-1964-377628-normaatualizada-pl.pdf.

Martello, A. (2017, novembro 2). Agricultura familiar encolhe; assistência social tem alta: saiba quais áreas ganham e perdem no Orçamento 2018. Portal G1. https://g1.globo.com/economia/noticia/agricultura-familiar-encolhe-assistencia-social-tem-alta-saiba-quaisareas-ganham-e-perdem-no-orcamento-2018.ghtml

Martin, J., \& Fernandes, B. (2004). Movimento socioterritorial e "globalização": algumas reflexões a partir do caso do MST. Lutas Sociais, (11/12), pp. 173-185. http://revistas.pucsp.br/ls/article/view/18710

Ministério do Desenvolvimento Agrário. (2013). Roteiro para criação de projeto de assentamento Casulo (PCA). Brasília, Brasil: Ministério do Desenvolvimento Agrário.

Muller, P. (2005). Esquisse d'une théorie du changement dans l'action publique: structures, acteurs e cadres cognitifs. Revue française de sciense politique, 55(1), pp. 155-187. https://doi.org/10.3917/rfsp.551.0155

Muller, P. (2008). Les politiques publiques. Paris, França: PUF. 
Montagnini, F. (1992). Sistemas Agroforestales: principios y aplicaciones en los trópicos. San Jose, Costa Rica: Organización para Estudios Tropicales.

Oliveira, A. U. de. (2007, fevereiro 27). Os Números da Reforma Agrária do Governo Lula. Repórter Brasil. https://reporterbrasil.org.br/2007/02/os-numeros-da-reforma-agraria-do-governo-lula/.

PNOT (2006). Ministério da Integração Nacional. Documento base para a definição de uma Política Nacional de Ordenamento Territorial (versão preliminar). Brasília, Brasil: MI-SDR.

Peixoto, R. (2009). Caminhos e Descaminhos do Desenvolvimento Territorial no Pará. In G. de M. Rocha, S.B. Magalhães, \& P. Teiseerenc (Eds.), Territórios de Desenvolvimento e Ações Públicas (pp. 65-93). Belém, Brasil: EDUFPA.

Raffestin, C. (1993). Por uma geografia do poder. São Paulo, Brasil: Ática.

Rocha, A. C. (2015). O MST e a luta pela terra no Pará. Marabá, Brasil: Iguana.

Rua, M. das G. (2014). Políticas públicas. Florianópolis, Brasil: Departamento de Ciências da Administração da UFSC.

Sabourin, E. (2017). Enfoque Sistêmico e análise das políticas públicas rurais. Agricultura Familiar: Pesquisa, Formação e Desenvolvimento, 11(2), pp. 29-48. https://doi.org/10.18542/raf.v11i2.5315

Silva, J. A. C. e. (2016). Juventude rural e trabalho: o caso do Assentamento Mártires de Abril, Distrito de Mosqueiro. 2016 (tese de mestrado). Belém, Brasil: Universidade Federal do Pará.

Shanin, T. (2005). A definição de camponês: conceituações e deconceituações - o velho e o novo em uma discussão marxista. Revista NERA, 8(7), pp. 1-21.

Winnie, O. (2013). Dendê: o avanço do monocultivo ameaça a agricultura familiar na Amazônia paraense. http://www.br.boell.org/sites/default/files/monocultivododendeentrevistawinnie_overbeek.pdf

Woortmann, E. F. (2009). O saber camponês: práticas ecológicas tradicionais. In E. P. de Godoi, M. A. Menezes, \& R. A. Marin (Eds.), Diversidade do campesinato: expressões e categorias. Estratégias de Reprodução Social (vol. 2, pp. 119-129). São Paulo, Brasília, Brasil: UNESP, NEAD. 
